\title{
Designing and Developing of Savonius Wind Turbine for Efficiency Improvement in Low-Speed Wind Sources
}

\author{
Nantasak Sukrurkdee, Punyawee Bumroongrads, Peerapol Sangsawat, and Chawannat \\ Jaroenkhasemmeesuk
}

\begin{abstract}
Wind energy is one of the highest efficiency in renewable energy. Unfortunately, wind energy was not developed much in Thailand because the average wind speed of the city area is limited to the medium-low range which makes wind energy unsuitable for power generation. Recently, there are the researches tried to apply the wind turbine to wind source besides the bus. According to a large amount of vehicles transport from upcountry into the city $5 n$ Thailand, wind energy can be considered as the potential energy only if the turbine can operate the high efficiency. With this reason, the object of this project focuses on the efficiency factors of a wind turbine to be able to use in low-speed wind energy especially wind that source by the passenger car includes designing and developing wind turbine for propeller's efficiency increasing. This project used 200-Watt Savonius wind turbine to experiment with the effect of 1) weight of propeller, 2) material of propeller, and 3) swept area of the propeller to the efficiency of the wind turbine. The research and experiment yield the results that all factors are affecting to RPM, electric power and efficiency of Savonius wind turbine. This project can increase the efficiency of small wind turbine about $26 \%$ for use in low-speed wind sources.
\end{abstract}

Index Terms-Renewable energy, wind turbine, efficiency, low-speed wind.

\section{INTRODUCTION}

The demand for electricity in Thailand is currently higher than the production every year. Fossil fuel is one of the most important fuel to generate electricity, but it causes the major problem of global warming by the emission of greenhouse gas, dust, etc. Moreover, imported fossil fuel may insufficient and leads to independence. With this reason, renewable and alternative energy is researched to promote sustainability such as hydropower, solar energy, etc. The growing trend of renewable energy is higher every year and it should be operated the same percentage as fossil fuel in 2040 [1]. Unfortunately, one of the highest efficiency technologies to generate electricity, wind power, is not interesting much in Thailand especially in the city area. Average wind speed of the city area in Thailand is the medium-low range that is lower than $4-5 \mathrm{~m} / \mathrm{s}$ as shown in Fig. 1 . The fastest wind speed is on the island in the Gulf of Thailand about $5.5 \mathrm{~m} / \mathrm{s}$ [2]. The problem of using a wind turbine to generate electricity is the speed of the wind that makes wind turbine in Thailand isn't

Manuscript received July 20, 2019; revised October 9, 2019. This work was supported in part by the Department of Mechanical Engineering, Faculty of Engineering, Mahidol University.

The author are with the Department of Mechanical Engineering, Faculty of Engineering, Mahidol University, Nakorn Pathom, 73170 Thailand (e-mail: chawannat.jar@mahidol.ac.th). famous because the wind speed was considered too low.

There are two main types of wind turbines, horizontal and vertical axis. All types of wind turbines have varying designs, and different advantages and disadvantages. Advantages of using vertical wind turbine are easy to maintain, easy to rotate with low wind speed, not directional and lower construction and transportation costs. A vertical axis wind turbine is better than horizontal axis wind speed when it uses with the low-speed wind [3]. The wind turbine was researched and adapted to use in various situations such as using with rotatable gear or another source to increase the efficiency of the wind turbine. An energy harvesting such as wind turbines on the highway was researched and found that the efficiency of 34.6 percent was obtained [4].

In 2018, Bangkok is the 8th place of the capital city that has the worst traffic. According to the vehicles data in Thailand, it has a lot of vehicles driving across the city which may be a good opportunity to use the wind beside the vehicle as optional sources.

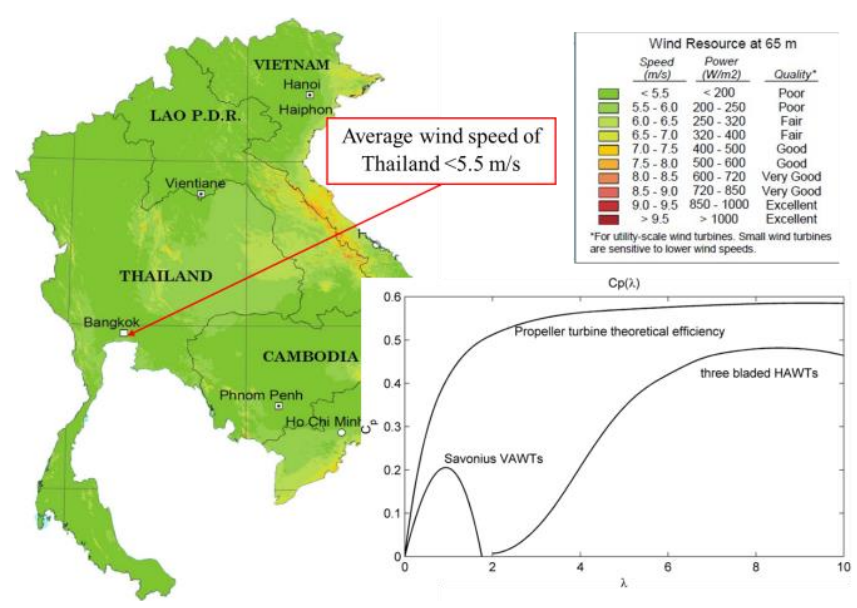

Fig. 1. Wind speed ability in Thailand and the efficiency of Savonius wind turbine.

The global trend of clean energy is the motivation of this project by using a Savonius wind turbine to generate electricity from the wind beside the vehicles. The main objective is designing and improvement a Savonius wind turbine to use with a low wind speed of the vehicle for propeller's efficiency increasing. The factors of designing and improvement include the weight of propeller, the material of propeller, swept area of the propeller [5]. The control parameters of this wind turbine are twin blade, rotating in clockwise, 200 watts of a generator and using low wind speed as the source.

The average speed of the vehicle crossing the city to Bangkok is $50-80 \mathrm{~km} / \mathrm{hr}$. This speed was collected from the 
standard vehicle in Thailand include a sedan, hatchback, minivan, and crossover. Wind speed beside the car was simulated from Autodesk Flow Design in Fig. 2 to analyze the form and velocity of wind beside a car to set the wind sources in the experiment. The wind is increasing when the car passed, then the fastest speed is between 55 and $85 \mathrm{~cm}$ of car height from the ground.

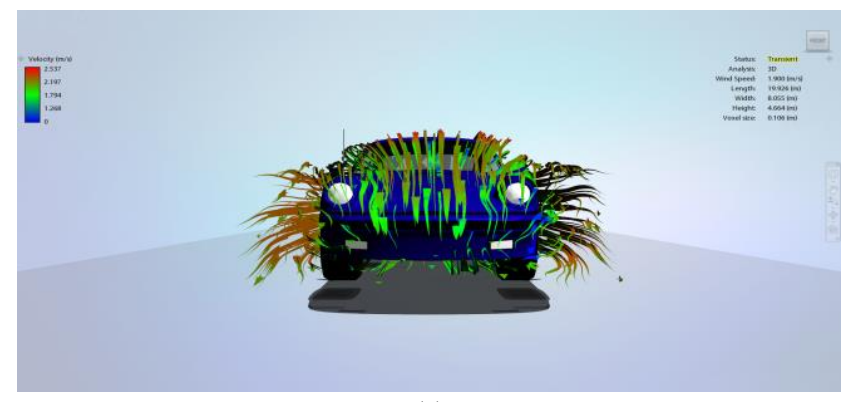

(a)

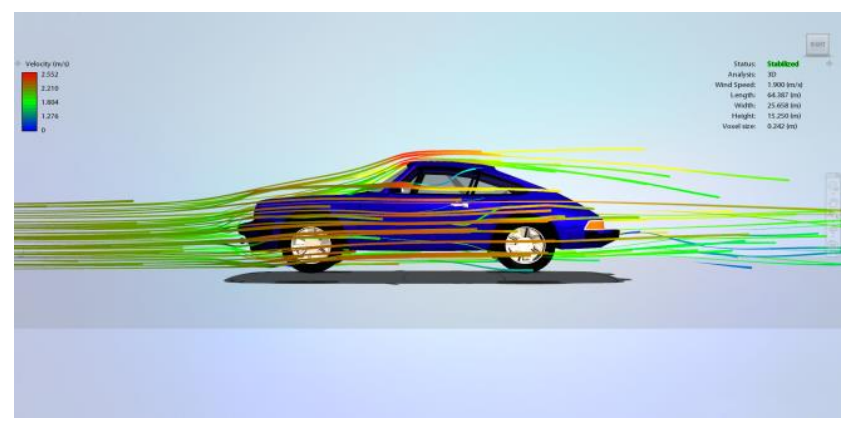

(b)

Fig. 2. The wind profile in front of a car model at $6.84 \mathrm{~km} / \mathrm{hr}$ (a) Front view (b) Side view.

The efficiency of a wind turbine $\left(C_{p}\right)$ as shown in (1) is the comparison between wind turbine power $\left(P_{w}\right)$ and wind power $\left(P_{a}\right)$. Equation of wind turbine efficiency can be solved by Eq. (1), where $V$ is voltage, $I$ is electric current (Amp), $\eta g$ is generator efficiency, $\eta c$ is controller efficiency, $\rho$ is air density $\left(\mathrm{kg} / \mathrm{m}^{3}\right), \mathrm{A}$ is the swept area $\left(\mathrm{m}^{2}\right), V$ is wind speed $(\mathrm{m} / \mathrm{s})$ [5], [6].

$$
C_{p}=\frac{P_{w}}{P_{a}}=\frac{V \times I}{1 / 2 \times \eta_{g} \times \eta_{c} \times \rho \times A \times v^{3}}
$$

A Savonius wind turbine is one of the famous types of vertical axis wind turbine that is good to use in Thailand because it is high efficiency with low speed. Savonius wind turbines are a type of vertical axis wind turbine, used for converting the force of the wind into torque on a rotating shaft. Specification of the Savonius wind turbine is a curve of propeller that is impacted by the wind. The ideal efficiency of the Savonius wind turbine is 0.2 .

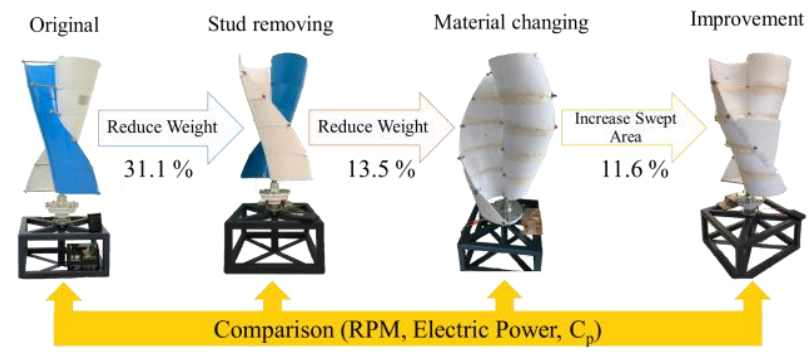

Fig. 3. Step of improvement of Savonius wind turbine in this work.

\section{MeTHODOLOGY}

\section{A. The Wind Profiles and Wind Source Setting Up}

The testing of the low wind speed at each position is the way let us know the profile of wind speed. Testing uses an anemometer to test the speed at $10-100 \mathrm{~cm}$. from the ground and $1.5 \mathrm{~m}$. from the center of the source. After that the wind profile was predicted by using linear regression analysis as shown in Fig. 4.

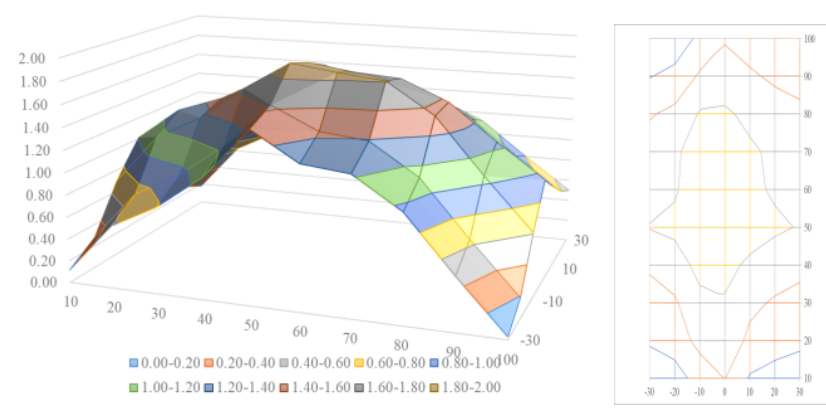

Fig. 4. Wind source profiles $(\mathrm{m} / \mathrm{s})$ at various height and offset.

The profiles of wind sources were analyzed using the speed and amount of wind to design the height area to increase the swept area as shown in Table I. Table I shows the percent of average speed from wind source which was divided into various height range. Case 4 shows the most effective range to analyze and design to expand the area of a wind turbine in 40-60 height. This work selected the 4 th case to be the first improving.

TABLE I: PERCENT of AVERAGe SPEEd At EACH CASE

\begin{tabular}{|c|c|c|c|c|c|c|}
\hline \multirow{2}{*}{$\begin{array}{l}\text { Height } \\
(\mathrm{cm})\end{array}$} & \multicolumn{6}{|c|}{ Percentage of wind (speed and amount) } \\
\hline & Case1 & Case 2 & Case 3 & Case4 & Case 5 & Case6 \\
\hline 90 & 7.7 & \multirow{2}{*}{18.5} & 7.7 & \multirow{3}{*}{31.7} & 7.7 & 7.7 \\
\hline 80 & 10.8 & & 230 & & 10.8 & \multirow{3}{*}{37.7} \\
\hline 70 & 13.1 & \multirow{2}{*}{27} & 25.9 & & \multirow{3}{*}{41.4} & \\
\hline 60 & 13.8 & & 283 & \multirow{3}{*}{42.2} & & \\
\hline 50 & 14.5 & \multirow{2}{*}{28.4} & 20.5 & & & \multirow{3}{*}{40.1} \\
\hline 40 & 14 & & & & \multirow{3}{*}{35.2} & \\
\hline 30 & 11.7 & \multirow{2}{*}{21.3} & 25.1 & \multirow{3}{*}{26.1} & & \\
\hline 20 & 9.5 & & \multirow{2}{*}{14.4} & & & 9.5 \\
\hline 10 & 4.9 & 4.8 & & & 4.9 & 7.4 \\
\hline
\end{tabular}

\section{B. Rotating Test, Electric Power and Retardation Time Test}

Rotating, electric power and retardation time test the original Savonius wind turbine to compare with material changing and new design wind turbine [7]. Material is changed to lighter material then, remove the stud of the propeller to reducing weight. Designing the wind turbine by increasing a swept area that is impacted by wind. The designing wind turbine is referred to case 4 of Table I that the fastest average speed is between $65-85 \mathrm{~cm}$. adding the swept about $680 \mathrm{~cm}^{2}$ by using coroplast because it isn't heavy. The testing is referred to wind profile that is tested at 65 and 80 $\mathrm{cm}$. from ground and 1.5, $3 \mathrm{~m}$ from the source.

\section{RESUlT AND DiscUSSION}

As mention above, the improvement of a wind turbine in 
this work includes 1) weight of propeller, 2) material of propeller, and 3) swept area of the propeller. For the weight of propeller, the studs in wind turbine installation set were removed, the weight of installation set decreases to $0.666 \mathrm{~kg}$ from $2.154 \mathrm{~kg}$ that is about $69 \%$ of the original decreasing. The wind turbine after stud removing was analyzed the wind resistance and found that it can resist the wind to $40 \mathrm{~m} / \mathrm{s}$. The material of propeller was changed to reduce the weight of propeller which was decreased to $2.274 \mathrm{~kg}$ form $2.628 \mathrm{~kg}$ (about $13.5 \%$ of the original).

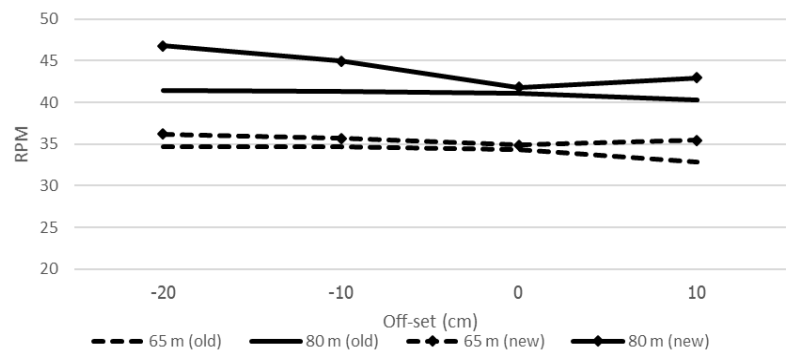

(a)

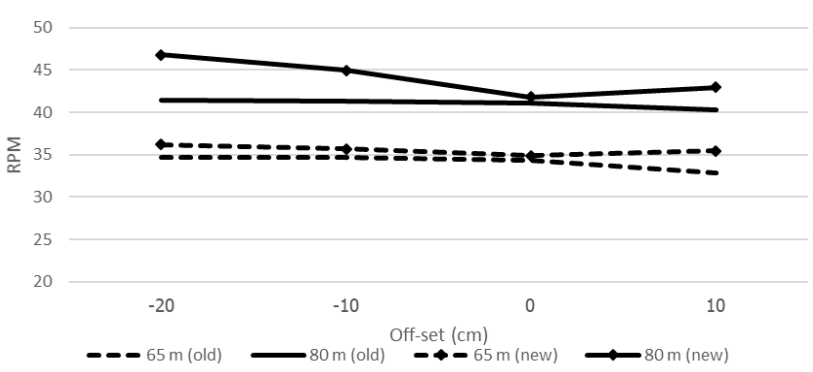

(b)

Fig. 5. The relationship between Off-set and RPM at 65 and $80 \mathrm{~cm}$ (a) with load (b) without load.

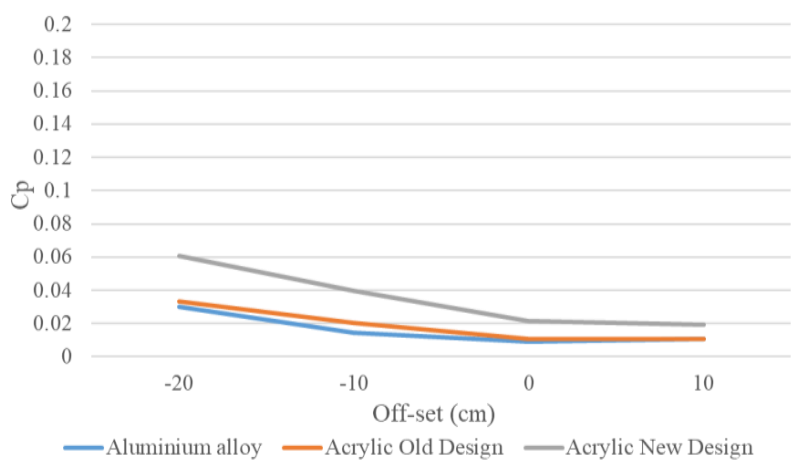

(a)

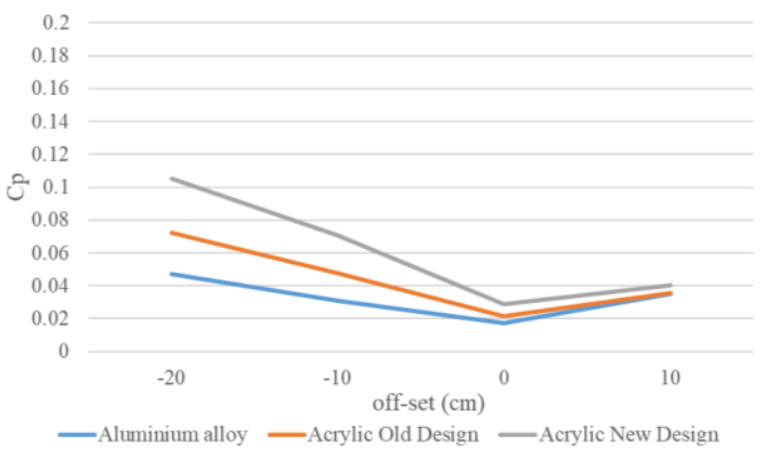

(b)

Fig. 6. The relationship between offset and power coefficient of three wind turbines (A) $65 \mathrm{~cm}$ (B) $80 \mathrm{~cm}$.
The designing wind turbine was increased the swept area by adding coroplast in case 4 area. The swept area was increased to $6,612.2 \mathrm{~cm}^{2}$ from $5,932 \cdot 2 \mathrm{~cm}^{2}$. Each step of wind turbine improvement was experimented to investigate rotating, electric power generation and retardation time. The result was shown in Fig. 5-7.

The Fig. 5 shows that the rotation cycle of both graphs has a similar trend, but different in the rotation cycle. Therefore, at the height of the wind source $80 \mathrm{~cm}$, can perform higher rotation cycle than $65 \mathrm{~cm}$. The aluminum alloy blade will have the highest rpm speed at the side of the side equal to 20 $\mathrm{cm}$ on the left thread. The acrylic and leaf designs that have been updated will have the highest speed per minute at the side distance of $10 \mathrm{~cm}$ on the left thread. The result of an improved wind turbine can increase the rotation by about $33 \%$, which will affect the next experiment, power generations.

The power coefficient of each improved wind turbine has a similar trend as shown in Fig. 6. By showing that the trend of properties is best in the offset at $20 \mathrm{~cm}$, both the origin of the high wind 65 and $80 \mathrm{~cm}$. From the study, it was found that the maximum efficiency of the Savonius wind turbine was 0.2 , as shown in Fig. 1. When the maximum value is compared as the percentage of the maximum efficiency at the side- $20 \mathrm{~cm}$ of the aluminum alloy impeller, acrylic propeller and the propeller designed to improve. It was found that at the height of $65 \mathrm{~cm}$ wind source, the highest percentage was 14.93 , 16.68 , and 30.24 , respectively at the height of $80 \mathrm{~cm}$. The highest percentage was 23.6, 36.23 and 52.62 respectively. From the original $26 \%$.

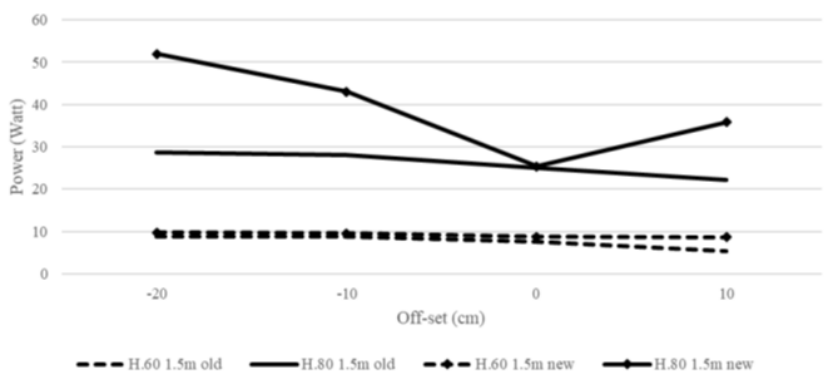

(a)

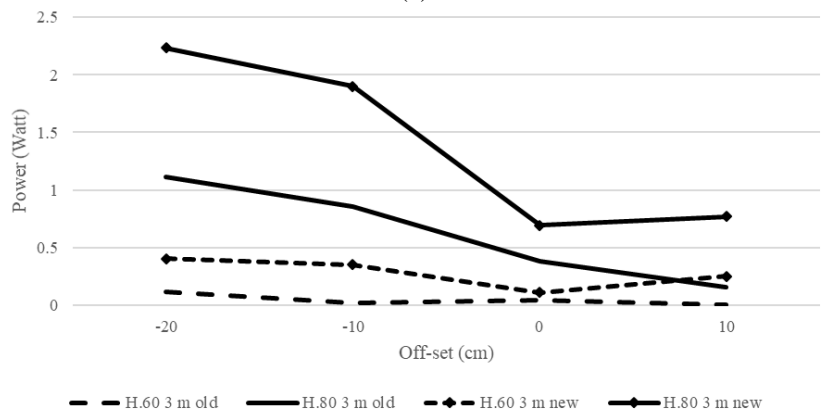

(b)

Fig. 7. The comparison of electric production of an original and improved wind turbine at (a) $1.5 \mathrm{~m}$ (b) $3 \mathrm{~m}$ of wind source.

Fig. 7. shows that the weight of struts and propellers effect on the generation of electricity in the absence of wind speed. Due to the wind speed from the side wind at $3 \mathrm{~m}$, which is very low, so there is very little difference between the power generation in this period or almost no effect at all. In the other way at $1.5 \mathrm{~m}$ of wind sources, the improved wind turbine can 
increase the electric production from $10 \mathrm{~W}$ to $50 \mathrm{~W}$.

\section{CONCLUSION}

From the testing of the performance of the Savonius wind turbine, the experiment found that the results were satisfactory and achieved the intended purpose and scope. The efficiency of the wind turbine $(\mathrm{Cp})$ using with low-speed wind source can be improved by reducing the weight of wind turbines and increasing the airflow area of the propeller using the wind profile of the car side wind. The calculations show that the energy coefficient has increased significantly with a maximum value of $52.62 \%$ compared to the mathematical theory which has seen a higher value from the original $26 \%$. By testing the delay of the time (seconds) that the propeller is still spinning when there is no source of wind to test the power produced during the rotor phase is stopped, it is found that the power has a low power during that period. Thus, it can be concluded that reducing weight does not affect electricity production in improvement and design. According to the improved efficiency, the upgrading wind turbine should be able to be installed and operated on the highway and motorway with 2-digit code in Thailand.

\section{ACKNOWLEDGMENT}

This research was supported by the Department of Mechanical Engineering, Mahidol University. Thanks to Sustainable and Renewable Laboratory (SURE), Mahidol University.

\section{REFERENCES}

[1] Department of Alternative Energy Development and Efficiency, Ministry of Energy, Thailand Alternative Energy Development Plan: AEDP2015. [Online]. Available: http://www.dede.go.th/download/ files/AEDP2015_Final_version.pdf

[2] C. Sinsabvarodom, P. Plodpradit, T. Phanyasahachart, B. J. Kim, G. L. F. Chiu, and K. D. Kim, "Feasibility study of offshore wind turbine substructure in the gulf of Thailand," in Proc. the 20th National Convention on Civil Engineering, 8-10 July, 2015, Thailand.

[3] H. Belmili, R. Cheikh, T. Smail, N. Seddaoui, and R. W. Biara, "Study, design and manufacturing of hybrid vertical axis Savonius wind turbine for urban architecture," Energy Procedia, vol. 136, pp. 330-335, 2017.

[4] E. Banihani, A. Sedaghat, M. Alshammari, A. Hussein, H. Kakuli, and A. Al Shuaib, "Feasibility of highway energy harvesting using a vertical axis wind turbine," Energy Engineering: Journal of the Association of Energy Engineers, vol. 115, 2018.

[5] E. H. Bani-Hani, A. Sedaghat, M. AL-Shemmary, A. Hussain, A. Alshaieb, and H. Kakoli, "Feasibility of highway energy harvesting using a vertical axis wind turbine," Energy Engineering, vol. 115, no. 2, pp. 61-74, 2018.

[6] M. H. Ali, "Experimental comparison study for savonius wind turbine of two \& three blades at low wind speed," International Journal of Modern Engineering Research (IJMER), vol. 3, no. 5, pp. 2978-2986, 2013.

[7] W. Roynarin, Optimization of Vertical Axis Wind Turbines, Northumbria University, 2014.

Nantasak Sukrurkdee is the senior students from the Department of Mechanical Engineering, Faculty of Engineering at Mahidol University, Thailand. He will receive their B.Eng. in 2019.

Punyawee Bumroongrads is the senior students from the Department of Mechanical Engineering, Faculty of Engineering at Mahidol University, Thailand. He will receive their B.Eng. in 2019

Peerapol Sangsawat is the senior students from the Department of Mechanical Engineering, Faculty of Engineering at Mahidol University, Thailand. He will receive their B.Eng. in 2019.

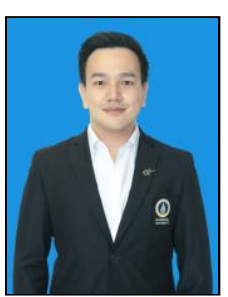

Chawannat Jaroenkhasemmeesuk was born in Chiang Mai, Thailand on July 15, 1985. His educational background Ph.D. (mechanical engineering) from Chiang Mai University, Thailand, 2017, M.Eng. (energy economics and planning), Asian Institute of Technology, Thailand 2010, B.Eng. (mechanical engineering), Chiang Mai University, Thailand, 2006. His work focuses especially on alternative energy, upgrading bio-oil, and energy economics and planning.

He is currently an instructor of the Department of Mechanical Engineering at Mahidol University, Thailand. In 2011, He worked as the head of Business Developing Department in the Science and Technology Park project under Chiang Mai University, Thailand. His previous works focus on many resources in energy filed includes "Simulation analysis of the catalytic cracking process of biomass pyrolysis oil with mixed catalysts: optimization using the simplex lattice design of the experiments", the International Journal of Energy Research, special issue paper (2018) and "Efficiency Evaluation of Cooling Pad System for Green Swine Farm Using Computational Fluid Dynamics Simulation", The 32nd Conference of Mechanical Engineering Network of Thailand (ME-NETT34), 3-6 July 2018, Mukdahan, Thailand

Dr.Chawannat Jaroenkhasemmesuk is the technical committee for ICLCA since 2019, ICNEA since 2018. 